\title{
PREDICTORS OF SUBJECTIVE WELL-BEING AMONG OLDER GHANAIANS
}

\author{
B.N.L. CALYS-TAGOE ${ }^{1,2}$, S.A. HEWLETT ${ }^{3}$, P. DAKO - GYEKE ${ }^{4}$, A.E. YAWSON ${ }^{1,2}$, N.A. BAD- \\ DOO $^{1,2}$, N.A.H. SENEADZA ${ }^{1,2}$, G MENSAH ${ }^{1}$, N MINICUCI ${ }^{1,5}$, N NAIDOO ${ }^{6}$, S CHATTERJI $^{6}$, P $^{2}$ \\ KOWAL ${ }^{6,7}$ and R.B. BIRITWUM ${ }^{1}$ \\ ${ }^{1}$ Department of Community Health, University of Ghana Medical School, College of Health Sciences, Korle- \\ Bu, Accra, Ghana, ${ }^{2}$ Public Health Unit, Korle-Bu Teaching Hospital, Korle-Bu, Accra, Ghana, ${ }^{3}$ University of \\ Ghana Dental School, College of Health Sciences. University of Ghana, ${ }^{4}$ Department of Social and Behavioral \\ Sciences, School of Public Health, College of Health Sciences, University of Ghana, Legon, Accra, Ghana, \\ ${ }^{5}$ National Council Research, Institute of Neuroscience, Padova, Italy, ${ }^{6}$ World Health Organization, Multi- \\ Country Studies unit, Geneva, Switzerland, ${ }^{7}$ University of Newcastle Research Centre on Gender, Health and \\ Ageing, Newcastle, Australia.
}

DOI: $h t t p: / / d x$.doi.org/10.4314/gmj.v48i4.2

Corresponding author: Dr. Benedict N.L. Calys-Tagoe

E-mail: calys75@hotmail.com

Conflict of Interest: None declared

\section{SUMMARY}

Background: Later years of life are accompanied by many physical, emotional and environmental changes which may impact on the well-being of the individual. Many factors are known to influence the subjective well-being of older adults, but most, if not all of this information was the result of studies in the Western world. This study aimed at obtaining and documenting the predictors of subjective well-being (SWB) among older Ghanaians.

Methods: Data for the study was obtained from the WHO SAGE study. The single item measure of life satisfaction was used to determine subjective wellbeing. Descriptive statistics as well as logistic regression analysis were carried out to determine the predictors of SWB.

Results: A total of 4724 individuals aged 50 years and above responded to the questionnaires. Of these $50.4 \%$ were males. Following multivariate logistic regression analysis, age, sex, educational level, income and ethnic background were found to significantly affect the SWB of older Ghanaians. Being male was associated with higher level of SWB (OR=1.68; CI: $1.39-2.03)$. For those 50 years and above, being younger (50-59 years) was also associated with a high level of SWB $(\mathrm{OR}=17.72$; CI: 10.13-30.98). Earning a low income and having low educational level were both associated with low levels of SWB (OR=0.304; CI: 0.22-0.42; and $\mathrm{OR}=0.47$; CI: $0.37-0.60$ respectively). Ewes $(\mathrm{p}=0.027)$, Grumas $(p=0.002)$ and Mole-Dagbons $(p=0.04)$ had significantly higher SWB compared to the other ethnic groups.

Conclusion: Among older Ghanaians, factors that positively influence SWB are younger age, male sex, high educational level and high income.
Keywords: Subjective well-being, Life satisfaction, Older Ghanaians, SAGE study, Predictors

\section{INTRODUCTION}

Trends in ageing have been increasing in all regions of the world; Asia, Europe, Latin America/Caribbean, North America, Oceania and sub-Saharan Africa ${ }^{1}$. The older adult population has increased steadily since 1950 in all six regions. The highest overall proportion is in Europe; where by 2050 the aged proportion is estimated to be $36.6 \%$. For Asia, Latin America and North America, projections indicate that increases will bring the proportion of the aged to between $22 \%$ and $27 \%$ by 2050 , and in sub-Saharan Africa the projected population of the aged will be $10.2 \%{ }^{1}$ In Ghana, there is evidence of the ageing of the population, with the proportions aged 60 years and older rising from 4.6 in 1960 to 6.7 percent in 2010. Ageing may appear to be gradual at the moment but the older population will grow rapidly as the fertility transition advances. ${ }^{2}$

The later years of life are accompanied by many physical and emotional changes as well as changes in one's environment. Some of these changes, such as deteriorating health are gradual; whereas others, like the death of a spouse are sudden. However not all the changes associated with ageing are negative. The wisdom of experience, retirement and freedom from familial responsibilities can make later life a very positive part of the life cycle. An individual's ability to cope with these changes affects their subjective well-being. ${ }^{3}$

Subjective well-being (SWB) is defined as "a person's cognitive and affective evaluations of his or her life"3. 
The cognitive element refers to what one thinks about his or her life satisfaction in global terms (life as a whole) and in domain terms (in specific areas of life such as work, relationships, etc.) The affective element refers to emotions, moods and feelings. Affect is considered positive when the emotions, moods and feelings experienced are pleasant (e.g. joy, elation, affection etc.) Affect is deemed negative, though, when the emotions, moods and feelings experienced are unpleasant (e.g. guilt, anger, shame etc.). The terms subjective well-being, happiness, psychological well-being, positive affect, and morale are often used interchangeably. Although all of them refer to a positive orientation toward life, there are conceptual differences among them. The key factor hypothesized to distinguish between them is stability. ${ }^{4}$

Life satisfaction and morale are conceptualized as relatively stable orientations toward life that, though evaluative, are not affected by transient moods. Happiness is viewed as less stable and less cognitive than life satisfaction and positive affect is expected to be the least stable, changing rapidly and frequently in response to stimuli in the immediate environment. ${ }^{5}$

SWB is measured with three primary types of instruments. Most commonly used are "single-item measures" of life satisfaction and happiness. A second approach is "multi-item scales," such as the Philadelphia Geriatric Center (PGC) Morale Scale. ${ }^{6}$ A final strategy is "multidimensional scales" of which Ryff's Psychological Well-Being Index (PWI) ${ }^{7}$ and Diener's Satisfaction with Life Scale $(\mathrm{SWLS})^{8}$ are among the best known. Single-item measures are usually psychometrically inferior to multi-item (and, therefore, multidimensional) scales because of lower validity and reliability. That does not seem to be true, however, for single-item measures of subjective well-being. ${ }^{9}$

Single-item measures are especially likely to be used in social surveys and cross-national comparisons for two reasons. First, because they are short and secondly, because happiness and life satisfaction translate well across cultures, but some of the items in multi-item scales do not. ${ }^{9}$ Many factors are known to influence the subjective well-being of older adults. Campbell et al reported that age patterns of life satisfaction and happiness differ somewhat. Based on data from a representative national sample, they compared young, middleaged, and older adults. Older adults were the most satisfied with their lives, middle-aged adults were the least satisfied, and young adults were intermediate. With regard to happiness, however, young adults were happiest, the middle-aged were least happy, and older adults were intermediate. ${ }^{10}$
A consistent finding, based on data spanning 35 years, according to Yang is that the proportions of Americans who report high levels of SWB increases substantially with age. ${ }^{11}$ Using repeated cross-sectional surveys from 1972 to 2004, Yang found that older adults consistently reported higher levels of happiness than young and middle-aged adults ${ }^{11}$. An important contribution of the study by Yang is that age effects were estimated with the effects of period and cohort statistically controlled $^{11}$. Pinquart and Sorensen also reported a strong pattern of increasing SWB with age based on a metaanalysis of 286 studies. $^{12}$

For young and middle-aged adults, education and income are the strongest predictors of SWB. Their importance for SWB in late life is however less clear. ${ }^{9}$ In a meta-analysis of 286 studies, it was found that both education and income were robust predictors of SWB in later life, with income the stronger of the two. ${ }^{12} \mathrm{Ed}-$ ucation appears to confer a lifelong advantage for healthy ageing. ${ }^{13}$ It is significantly and positively related to adult subjective well-being ${ }^{14}$. Yang found that education significantly predicts happiness at most ages but is unrelated to happiness after age $50 .^{11}$

Income, however, was a significant predictor, and its potency did not diminish across age groups ${ }^{11}$. Some investigators report that education and income totally or partially mediate the effects of race/ethnicity on $\mathrm{SWB}^{15}$, and others report that the effects of socioeconomic status (SES) are independent of race. ${ }^{16}$ Being married is strongly and significantly related to higher SWB. ${ }^{17,11,18}$ This finding was based on a sample of more than 59,000 adults in 45 countries. A metaanalysis of 300 studies revealed that older married adults enjoy higher SWB than their unmarried peers. ${ }^{19}$ Several longitudinal studies demonstrate that transitioning out of marriage during later life is associated with decreases in SWB but that it rebounds to approximately pre transition levels within $1-2$ years. ${ }^{20,21}$

In a study conducted in 2007, it was found that, elderly individuals who looked to God for strength and comfort or decided what to do with God were more likely to have greater life satisfaction. ${ }^{13}$ Another study conducted to examine the multifaceted relationships between religious involvement and subjective well-being suggests that the beneficent effects of religious attendance and private devotion reported in previous studies are primarily indirect, resulting from their respective roles in strengthening religious belief systems. ${ }^{22}$

The positive influence of religious certainty on wellbeing, however, is direct and substantial: individuals with strong religious faith report higher levels of life satisfaction, greater personal happiness, and fewer neg- 
ative psychosocial consequences of traumatic life events. ${ }^{22}$ Further, in models of life satisfaction only, the positive influence of existential certainty is especially pronounced for older persons and persons with low levels of formal education. ${ }^{22}$ Thirty years of research among older Americans on life satisfaction, morale, and related constructs reported well-being to be most strongly related to health, followed by socioeconomic factors and degree of social interaction, for the general population of Americans over 60 years of age ${ }^{23}$. Marital status and aspects of people's living situations were also conclusively related to well-being ${ }^{23}$. According to Larson however, age, sex, race, and employment showed no consistent independent relation to wellbeing. ${ }^{23}$

The above mentioned studies, like several others on subjective well-being were carried out in the developed world, but little is known about the situation in developing countries like Ghana. However, developing countries are currently experiencing rapid demographic and health transitions, which are characterized by the growing older population and changing patterns of diseases $^{24,25}$ and improvement in quality of life or subjective well-being of this growing population group has become a global priority for policy. ${ }^{25}$

If the current trend in ageing is anything to go by, then more and more Ghanaians are expected to live longer leading to an increase in the proportion of the aged. The way people feel about their life (subjective wellbeing) as they grow older is obviously affected by a number of factors including their state of health and this to some extent determines whether they become assets or liabilities to those around them and the nation as a whole. Subjective well-being is therefore a very important subject that requires much attention in the Ghanaian setting.

Although the study of SWB in late life has a long and productive history, important work remains to be done $\mathrm{s}^{5}$ especially in the developing countries like Ghana where there is paucity of data on the subject. Information on the older population in Ghana is generally obtained from national census and other national surveys (demographic and health surveys and living standard surveys.) There is, however, a paucity of data from studies and surveys on the aged specifically. The census and other national surveys, although very useful, have limited periodicity of data collection and detail on the older population. ${ }^{26}$

This study therefore seeks to identify some predictors of SWB among older Ghanaians. In this study "older adult/older Ghanaian" refers to any Ghanaian aged 50 years and above. The study determined the socio de- mographic characteristics, assessed the subjective wellbeing and determined the factors associated with subjective well-being of the older Ghanaian. It is believed that the findings will be useful in policy formulation and planning of services for the aged in Ghana.

\section{Brief background of $S A G E$}

The World Health Organization's Study on Ageing (SAGE) and Adult Health survey evolved from the World Health Survey (WHS) of 2002-2004, which was organized as collaboration among W.H.O. the Ministry of Health through the National Health Research Unit and the University of Ghana Medical School through the Department of Community Health. The SAGE survey was carried out in six countries; China, Ghana, India, Mexico, the Russian Federation and South Africa. The goal of the SAGE survey was to strengthen, gather, process and manage data on older persons and to respond to identified needs via policy, planning and research. $^{26}$

\section{MATERIALS AND METHODS}

The SAGE survey was undertaken in Ghana by the WHO as part of a multi-country longitudinal study to complement the existing ageing data sources for monitoring policy goals and programmes. This study was based on data from SAGE in Ghana.

A nationally representative sample was used for the survey. Primary sampling units (PSUs) in defined enumeration areas (EA) were stratified by region and location (urban/rural). Selection of the EAs was based on proportional allocation by size. Each enumeration area (EA) was selected independently within each stratum. Twenty households were randomly selected in each EA using systematic sampling.

The number of EAs per region was based on the population size of the region. Within each EA, 20 households with one or more $50+$ individuals were selected. All the $50+$ year olds within the selected households were then interviewed face-to-face regarding their household characteristics, socio-demographic and work history, perceived health status, risk factors and preventive health behaviors, chronic conditions and health services coverage, health care utilization, subjective well-being and quality of life, and social cohesion. In addition, anthropometric measurements were recorded and blood spots for biomarkers were collected. Respondents also completed performance tests.

Field work and data entry were undertaken between May 2007 and June 2008. The total household population was 27988 from 5266 households. 
In assessing subjective well-being, respondents were asked whether they had enough money and energy to meet their daily needs.

They were also asked how satisfied they were with their health, themselves, their ability to perform daily living activities (this may be lacking or limited by disability despite having the energy required for these activities), their interpersonal relationships and the conditions of their living place (place of abode). Then they were asked how satisfied they were with life putting all the above together. Their response to this last question was used as the single item measure for SWB in this study. ${ }^{27}$

The detailed methods for data collection in the SAGE have been described by Kowal et al. ${ }^{28}$

\section{Data Analysis}

The effect of the following variables of interest on life satisfaction as a proxy measure for SWB were assessed in this study; age of respondents, sex of respondents, ethnic background, current marital status, highest level of education completed, income quintile of respondent, religious denomination/affiliation.

Although SWB can be measured using three primary types of instruments, this study used the single item measure of life satisfaction as a measure for SWB because happiness and life satisfaction translate well across cultures, but some of the items in multi-item scales do not.

Descriptive statistics (frequencies, percentages, means and standard deviations) were calculated. Bivariate analyses as well as multinomial logistic regression analysis were also carried out at the $95 \%$ confidence level to establish any relationship between the independent variables and the outcome variable (level of satisfaction with life). The level of satisfaction with life was measured on a likert scale ranging from 1(very dissatisfied with life) through to 5 (very satisfied with life).

This was recoded into two groups for the purpose of logistic regression. Group 1 (satisfied with life) was made up of those who answered "satisfied" and "very satisfied" to the question on "level of satisfaction with life" while group 2 (not satisfied with life) was made up of those who answered "very dissatisfied", "dissatisfied" and "indifferent/neutral" to that question.

\section{RESULTS}

Information was obtained from 4,724 respondents from all the ten regions of Ghana. They were made up of 2379 (50.4\%) males and 2,345 (49.6\%) females, with ages ranging from 50 years to 120 years. The mean age was $64.2 \pm 10.73$ years and the median age was 62 years. The socio demographic characteristics of these respondents are shown in Table 1.

After univariate analysis the following factors were found to be significant: age $(\mathrm{p}<0.0001)$, sex $(\mathrm{p}<0.0001)$, educational level $(\mathrm{p}<0.0001)$, income $(p<0.0001)$, ethnic background $(p=0.004)$ and marital status $(p=0.048)$. Of these factors thought to influence SWB, age, sex, educational level, income and ethnic background were found to be significant among older adults in Ghana following multivariate analysis (Table 2).

Table 1 Socio demographic characteristics of respondents

\begin{tabular}{|l|l|l|l|}
\hline Variables & $\begin{array}{l}\text { Male } \\
\text { N (\%) }\end{array}$ & $\begin{array}{l}\text { Female } \\
\text { N (\%) }\end{array}$ & $\begin{array}{l}\text { Total } \\
\text { N }\end{array}$ \\
\hline Age Group & & & $(\mathrm{n}=4724)$ \\
$50-59$ & $1002(53.2)$ & $880(46.8)$ & 1882 \\
$60-69$ & $697(53.3)$ & $611(46.7)$ & 1308 \\
$70-79$ & $468(43.8)$ & $601(56.2)$ & 1069 \\
$80-89$ & $159(44.2)$ & $201(55.8)$ & 360 \\
$\geq 90$ & $53(50.5)$ & $52(49.5)$ & 105 \\
\hline Marital Status & & & $(\mathrm{n}=4697)$ \\
Never married & $28(48.3)$ & $30(51.7)$ & 58 \\
Currently married & $1953(72.3)$ & $749(27.7)$ & 2702 \\
Co habiting & $24(64.9)$ & $13(35.1)$ & 37 \\
Separated/Divorced & $193(30.9)$ & $431(69.1)$ & 624 \\
Widowed & $166(13)$ & $1110(87)$ & 1276 \\
\hline Educational level* & & & $(\mathrm{n}=4697)$ \\
Low & $1538(43.4)$ & $2007(56.6)$ & 3545 \\
High & $829(72)$ & $323(28)$ & 1152 \\
\hline Income level (in & & & $(\mathrm{n}=4717)$ \\
quintiles) & & & \\
Q1 & $450(48)$ & $488(52)$ & 938 \\
Q2 & $437(46.5)$ & $502(53.5)$ & 939 \\
Q3 & $466(49.1)$ & $483(50.9)$ & 949 \\
Q4 & $483(51.8)$ & $450(48.2)$ & 933 \\
Q5 & $541(56.5)$ & $417(43.5)$ & 958 \\
\hline Ethnicity & & & $(\mathrm{n}=4227)$ \\
Akan & $956(46.4)$ & $1105(53.6)$ & 2061 \\
Ewe & $138(47.4)$ & $153(52.6)$ & 291 \\
Ga-Adangbe & $218(49.9)$ & $219(50.1)$ & 437 \\
Gruma & $110(51.2)$ & $105(48.8)$ & 215 \\
Grusi & $30(71.4)$ & $12(28.6)$ & 42 \\
Guan & $36(55.4)$ & $29(44.6)$ & 65 \\
Mande-Busanga & $39(61.9)$ & $24(38.1)$ & 63 \\
Mole-Dagbon & $72(67.3)$ & $35(32.7)$ & 107 \\
Others & $637(67.3)$ & $309(32.7)$ & 946 \\
\hline
\end{tabular}

*Formal education up to secondary level was classified as low while levels above secondary were classified as high.

${ }^{* *}$ Q1 represents the poorest while Q5 represents the richest

Increasing age was associated with decreasing levels of SWB such that the $50-59$ year group had the highest level of SWB (OR=17.72; CI: 10.13-30.98). Satisfaction with life then decreases with increasing age with those 90 years or older being the least satisfied. 
Table 2 Significant predictors of life satisfaction (subjective well-being)

\begin{tabular}{|c|c|c|c|}
\hline Variables & Odds ratio* & \multicolumn{2}{|c|}{$\begin{array}{l}\text { Confidence Interval } \\
\text { Lower boundary Upper } \\
\text { boundary }\end{array}$} \\
\hline $\begin{array}{l}\text { Age (years) } \\
50-60 \\
60-69 \\
70-79 \\
80-89 \\
\geq 90\end{array}$ & $\begin{array}{l}17.72 \\
11.00 \\
6.92 \\
3.80 \\
1.00\end{array}$ & $\begin{array}{l}10.13 \\
6.288 \\
3.96 \\
2.09 \\
-\end{array}$ & $\begin{array}{l}30.98 \\
19.24 \\
12.08 \\
6.89 \\
-\end{array}$ \\
\hline $\begin{array}{l}\text { Sex } \\
\text { Male } \\
\text { Female }\end{array}$ & $\begin{array}{l}1.68 \\
1.00\end{array}$ & $\begin{array}{l}1.39 \\
-\end{array}$ & $\begin{array}{l}2.03 \\
-\end{array}$ \\
\hline $\begin{array}{l}\text { Educational Level } \\
\text { Low } \\
\text { High }\end{array}$ & $\begin{array}{l}0.47 \\
1.00\end{array}$ & $\begin{array}{l}0.37 \\
-\end{array}$ & $\begin{array}{l}0.60 \\
-\end{array}$ \\
\hline $\begin{array}{l}\text { Income } \\
\text { Q1 } \\
\text { Q2 } \\
\text { Q3 } \\
\text { Q4 } \\
\text { Q5 }\end{array}$ & $\begin{array}{l}0.304 \\
0.345 \\
0.374 \\
0.581 \\
1.00\end{array}$ & $\begin{array}{l}0.22 \\
0.251 \\
0.272 \\
0.418 \\
-\end{array}$ & $\begin{array}{l}0.42 \\
0.476 \\
0.514 \\
0.806 \\
-\end{array}$ \\
\hline $\begin{array}{l}\text { Ethnic Back- } \\
\text { ground } \\
\text { Akan } \\
\text { Ewe } \\
\text { Ga-Adangme } \\
\text { Gruma } \\
\text { Grusi } \\
\text { Guan } \\
\text { Mande-Busanga } \\
\text { Mole-Dagbon } \\
\text { Others }\end{array}$ & $\begin{array}{l}1.00 \\
1.61 \\
1.35 \\
2.10 \\
2.72 \\
2.19 \\
1.53 \\
2.02 \\
1.39\end{array}$ & $\begin{array}{l}- \\
1.05 \\
0.97 \\
1.31 \\
0.82 \\
0.86 \\
0.66 \\
1.03 \\
1.08\end{array}$ & $\begin{array}{l}- \\
2.44 \\
1.87 \\
3.37 \\
8.97 \\
5.61 \\
3.45 \\
3.97 \\
1.78\end{array}$ \\
\hline
\end{tabular}

*Q1 represents the lowest quintile ("poorest") while Q5 represents the highest quintile ("richest")

Older Ghanaian males have significantly higher SWB $(\mathrm{OR}=1.68$, CI: 1.39-2.03) compared to older Ghanaian females. Ones level of education was also found to affect subjective well-being. Those with lower educational levels (ie. those with secondary education or less) have a lower level of SWB compared with those who have attained educational status beyond the secondary level.

Higher wealth quintiles were associated with higher levels of SWB. Compared to those in the highest quintile (Q5), those in the lowest quintile (Q1) have the lowest level of SWB (OR=0.304; CI: $0.22-0.42)$. Levels of SWB improve from the lower to higher wealth quintiles.

Levels of subjective well-being were similar among most of the ethnic groups except for the Ewes $(\mathrm{p}=0.027)$, Grumas $(\mathrm{p}=0.002)$ and Mole-Dagbons $(\mathrm{p}=0.04)$ who had significantly higher levels of SWB.

Marital status was weakly associated with SWB after univariate analysis, but was not significant following multivariate analysis. Religious affiliation and having someone to trust or confide in were not found to significantly affect SWB in this study.

\section{DISCUSSION}

Age was found to significantly influence ones level of SWB as was the case in most other studies on SWB. ${ }^{10,12}$ However contrary to the finding of Yang among Americans that older adults reported higher levels of SWB ${ }^{11}$, this study found the level of SWB to be highest among the $50-59$ year group and then decrease gradually as age increases. This could be the result of factors like the lack of day care and recreational facilities for the aged and the absence of a properly functioning social welfare system in Ghana contrary to what pertains in the developed countries.

Another factor that was found to significantly influence SWB was sex. Compared to their female counterparts, older Ghanaian males have significantly higher levels of SWB. This finding could probably be due to the fact that Ghanaian males usually attain higher educational levels and earn higher incomes compared to their female counterparts. Education and income are both positively associated with SWB and therefore the sex difference could be the indirect impact of education and income both of which were significant in this study.

Education was another predictor of SWB. Those with high (above secondary) educational level had higher levels of SWB compared to those with low (secondary or lower) educational levels. Education is a wellknown and important factor for health in men and women. Higher education might be associated with better knowledge about health matters, leading to better health conditions and, consequently, yielding higher levels of SWB. This is consistent with that from previous studies. ${ }^{9}, 12,13,14$

As one would expect, income was a strong predictor of SWB in this study. Those in the higher income quintile had higher levels of SWB compared to those in the lower quintiles with those in the lowest income quintile (Q1) having the least level of SWB. The more financially adequate the older Ghanaians felt, the higher the level of SWB they reported. This was also consistent with other studies by Pinquart and Sorensen as well as Diener et al. ${ }^{9,} 12$

With regards to ethnic groupings, the Ewes, the Grumas and the Mole-Dagbons had significantly higher levels of SWB compared to the other ethnic groups. Most studies compared Blacks and Whites and reported that Black individuals are significantly less likely to report high SWB than White persons. ${ }^{15}$

No previous data was however available on the level of SWB among the various Ghanaian ethnic groups for comparison. 
These higher levels of SWB among the Ewes, Grumas and Mole-Dagbons may have a cultural base and further studies may be required to explore these differences.

Contrary to the findings of several studies, including that of Mroczek and Spiro, Yang and Diener et al, which identified marital status as significantly affecting $\mathrm{SWB}^{11,17,18}$, marital status was not found to significantly affect SWB in this study. Religious involvement also did not significantly affect SWB in this study as was found by Ellison. ${ }^{22}$ These findings were rather surprising because anecdotal evidence suggests that Ghanaians place a lot of premium on both marriage and religion.

In the case of religion, a possible explanation could be the fact that almost all $(94.6 \%)$ of the respondents had some religious affiliation and therefore the effect of religion on SWB of older Ghanaians could not be adequately ascertained from the sample used. However, the same could not be said of marriage as $60 \%$ of respondents were living with their partners (either married or cohabiting) and $40 \%$ were not living with partners (never married, widowed, separated or divorced).

\section{CONCLUSION}

For older Ghanaians aged 50 years and over, "being young", being male, having higher educational level and earning high income were found to be significantly associated with the reporting of high levels of SWB. Religious involvement and marital status were however, not found to significantly affect SWB in this study.

\section{RECOMMENDATIONS}

Based on the findings above, we wish to make the following recommendations:

The government should seriously consider ways of expanding and extending the free compulsory universal basic education (FCUBE) program beyond the basic to secondary and ultimately to tertiary levels as education beyond the secondary level significantly enhances SWB of the older Ghanaian adult.

This may also enhance their earning abilities during their years of active service and thus by extension help secure better pensions. Additionally, expansion of the pension scheme to include workers in the informal sector and education of this group of workers on the importance of saving or investing to safe guard their future will help improve their income in old age and thus improve their wellbeing. The sector ministry responsible for social welfare should collaborate with various stakeholders to revamp the social welfare system to be able to meet the needs of the ever increasing older adult population. This should include the establishment of day care facilities for the aged especially those with no family support.

\section{ACKNOWLEDGEMENT}

Financial support was provided by the US National Institute on Aging through an interagency agreement with the World Health Organization. WHO contributed financial and human resources to SAGE. The Ministry of Health, Ghana is supportive of SAGE. The University of Ghana's Department of Community Health contributed training facilities, data entry support and storage of materials. The Ghana Statistical Office provided the sampling information for the sampling frame and updates.

\section{REFERENCES}

1. United Nations Population Division . World population prospects: the 2012 revision. New York: United Nations, 2013.

2. Ghana Statistical Service . Population and Housing census, 2010: National Analytical report, 2013 page 54 .

3. Diener E, Oishi S, and Lucas RE. Subjective wellbeing: The science of happiness and life satisfaction. In Snyder CR. \& Lopez SJ. (Ed.), Handbook of Positive Psychology. Oxford and New York : Oxford University Press, 2002.

4. George LK. Perceived quality of life. In Binstock RH. and George LK. (Eds.), Handbook of aging and the social sciences, sixth edition. 2006; 320336. San Diego, CA: Academic Press.

5. George LK. . Still happy after all these years: research frontiers on subjective well-being in later life. Journal of Gerontology: Social Sciences. 2010;65(3):331-339

6. Lawton MP. The Philadelphia Geriatric Center Morale Scale: A revision. Journal of Gerontology. 1975; 30: 85-89.

7. Ryff CD, and Keyes CLM. The structure of psychological well-being revisited. Journal of Personality and Social Psychology.1995; 69: 719727.

8. Slocum-Gori SL, Zumbo BD, Michalos AC, and Diener E. A note on the dimensionality of quality of life scales: An illustration with the Satisfaction with Life Scale (SWLS). Social Indicators Research. 2009; 92: 489-496.

9. Diener E, Suh EM, Lucas RE, and Smith HL. Subjective well-being: Three decades of progress. Psychological Bulletin. 1999; 125: 276-301.

10. Campbell A, Converse PA, and Rodgers WL. The quality of American life. New York: Russell Sage Foundation, 1976. 
11. Yang Y. Social inequalities in happiness in the United States, 1972 to 2004: An age-period-cohort analysis. American Sociological Review. 2008; 73: 204-236.

12. Pinquart $\mathrm{M}$, and Sorensen $\mathrm{S}$. Influences of socioeconomic status, social network, and competence on subjective well-being in later life: A metaanalysis. Psychology and Aging. 2000;15: 187224.

13. Yoon DP. Factors Affecting Subjective WellBeing for Rural Elderly Individuals: The Importance of Spirituality, Religiousness, and Social Support. University of Missouri-Columbia, 2007

14. Meeks S, and Murrel SA. Contribution of Education to Health and Life Satisfaction in Older Adults mediated by Negative Affect. J. Aging Health. 2001;13(1): 92-119

15. Barger SD, Donoho DJ, and Wayment HA. The relative contributions of race/ethnicity, socioeconomic status, health, and social relationships to life satisfaction in the United Sates. Quality of Life Research. 2009; 18:179-189.

16. Hughes M, and Thomas ME.. The continuing significance of race revisited: A study of race, class, and quality of life in America, 1972 to 1996. American Sociological Review. 1998; 63: 785795.

17. Mroczek DK., and Spiro A. Change in life satisfaction during adulthood: Findings from the Veterans Affairs Normative Aging Study. Journal of Personality and Social Psychology. 2005; 88: 189-302

18. Diener E, Gohm CL, Suh E, and Oishi S. Similarity of relations between marital status and subjective well-being across cultures. Journal of CrossCultural Psychology. 2000; 3: 419-436.

19. Pinquart M, and Sorensen S. Gender differences in self-concept and psychological well-being in old age. Journal of Gerontology: Psychological Sciences. 2001; 56:195-213.
20. Chipperfield JG, and Havens B. Gender differences in the relationship between marital status transitions and life satisfaction in later life. Journal of Gerontology: Psychological Sciences. 2001; 56:176-186.

21. Lucas RE, Clark AE, Georgellis Y and Diener, E. Re-examining adaptation and the set-point model of happiness: Reactions to changes in marital status. Journal of Personality and Social Psychology. 2003; 84: 527-539.

22. Ellison CG. Religious involvement and subjective well-being: Journal of Health and Social Behavior. 1998; 25:700-720

23. Larson R. Thirty years of research on the subjective well-being of older Americans. Journal of Gerontology. 1978;33(1): 109-125.

24. Omran AR. The epidemiological transition theory revisited thirty year latter. World Health Stat $Q$ 1998; 51: 99-119.

25. World Health Organization. Active Aging: A Policy Framework. Geneva: World Health Organization, 2002.

26. University of Ghana, Department of Community Health . Ghana national report on World Health Organization's study on global AGEing and adult health (SAGE) in Ghana, Wave 1. Geneva: World Health Organization, 2014.

27. Witter RA, Okun MA, Stock WA and Haring MJ. Education and subjective well-being: A meta Analysis. Educational Evaluation and Policy Analysis. 1984;6(2):165-173

28. Kowal P, Chatterji S, Naidoo N, Biritwum R, Fan W, Ridaura RL, Maximova T, Arokiasamy P, Phaswana-Mafuya N, Williams S, Snodgrass J, Minicuci N, D’Este C, Peltzer K, BoermaJT and the SAGE Collaborators. Data Resource Profile: The World Health Organization Study on global ageing and adult health (SAGE). International Journal of Epidemiology. 2012;41:1639-1649 